Mesalazine is widely used in the treatment of in flam matory bowel disease. Little is known about the doseresponse relationship and about possible dose related side effects. In ulcerative colitis higher dosages of mesalazine $(3 \mathrm{~g})$ are more effective in maintaining a remission than lower dosages $(1.5 \mathrm{~g})$. In mild to moderately active ulcerative colitis, studies also indicate that higher dosages might be more effective in inducing remission. Dose-comparing studies in Crohn's disease are even more sparse, but the available results in dicate higher efficacy at $h$ igher dose levels.

None of the known side effects of mesalazine are clearly dose-related. A pH-dependent release system, however, can cause a sudden release of high doses of mesalazine. Consequent peak levels in serum have been implicated in mesalazine induced nephrotoxicity. In conclusion, despite the current practice of using increasing dosages of mesalazine in inflammatory bowel disease, both efficacy and safety have been established tentatively.

Key words: mesalazine, inflammatory bowel disease, Crohn's disease, ulcerative colitis, safety, side effects, drug therapy, dose-response

\section{Drug therapy: dose-response relationship of oral mesalazine in inflammatory bowel disease}

\author{
C. J. J. Mulder ${ }^{\mathrm{CA}}$ and S. J. van den Hazel
}

Department of Gastroenterology, Rijnstate Hospital, P O Box 9555, Arnhem, The Netherlands

\author{
${ }^{\mathrm{CA}}$ Corresponding Author \\ Fax: (+31) 263786737 \\ Email: cjmulder@worldonline.nl
}

\section{Introduction}

In recent years there has been a series of advances in the treatment of inflammatory bowel disease (IBD) (Crohn's disease and ulcerative colitis). Sulfasalazine was introduced into the treatment of IBD by Nana Swartz in the 1930s. ${ }^{1}$ It has been demonstrated in the late 1970 s that the the rapeutic activity of sulfasalazine is attributable to the local action of its mesalazine. ${ }^{2}$ New formulations of mesalazine have been developed in the 1980s with the aim of achieving liberation of the drug in the distal small intestine and the colon. ${ }^{3}$ Commonly used dosages in IBD are $1.5-4.8 \mathrm{~g}$ in divided dosages. ${ }^{4}$ However dose-response relations are insufficient reported in current literature to give sufficient guidelines. This article reviews the available studies for a dose response relation for mesalazine in IBD.

\section{Mesalazine}

Mesalazine preparations are established as the first line treatment for IBD being effective in the active disease state as well as maintaining patients in remission. ${ }^{4}$ In view of the trend for use of higher doses up to $4-6 \mathrm{~g}$ per day, it has become a matter of interest to determine which side-effects might be connected with the use of mesalazine. This means that patients need to take two $500 \mathrm{mg}$ microgranule tablets (Pentasa) four times per day. However, some patients cannot readily tolerate this number of tablets and therefore, a formulation containing $1 \mathrm{~g}$ of Pentasa microgranules per sachet has been developed as an alternative. In a volunteer study gastric emptying and colon filling rates associated with both formulations, the old and new, were the same. ${ }^{5}$ In pH-dependent formulations like Asacol, Claversal/Salofalk a problem in increasing the volume of mesalazine per tablet is the potential sudden release of the entire higher dosage of drug contents of the tablet in one area of the gastrointestinal tract when a $\mathrm{pH}$ favouring dissolution of the coating is encountered. This problem was illustrated in a pharmacokinetic comparison of Asacol, Claversal/Salofalk and Pentasa tablets. Claversal absorption was the highest of all. ${ }^{6}$ However more data about the new delivery systems like Asacol 800 are needed to allow physicians to choose with some degree of confidence which tablets to use for daily mesalazine dosages of 4-6g daily.

\section{Dose-dependent Adverse Effects}

The incidence of the common types of adverse effects associated with sulphasalazine correlates closely to the total sulfapyridine concentration in serum. The new sulfa-free salicylates are better tolerated than sulfasalazine. Adverse effects associated with mesalazine include headache, fever, 
rash, pneumonitis, pericarditis, pancreatitis, haemorrhagic colitis, diarrhoea, interstitial nephritis and muscle aches. The adverse effect of mesalazine that causes greatest concern is nephrotoxicity. It was suggested that the interstitial nephitis is caused by high serum peaks of mesalazine. ${ }^{7}$ Some suggested that this can only be reached with the pH-dependent formulations. However we have reported such side effect in a low daily dosage of $1.5 \mathrm{~g}$ Pentasa. ${ }^{8}$ Adequate epidemiological studies must recognize if side-effects like headache, fever etc. are dosedependent. Pericarditis and pancreatitis are probably not dose-dependent. ${ }^{9,10}$ We have to realize that methods of determining adverse events in trials are rather artificial, with compulsive, repeated openended questioning. Moreover, reporting of adverse events in journals is problamatic and gives no answer about the frequency or absolute numbers of side-effects.

\section{Dose-response in Efficacy}

Many investigators in the early 1980s believed that the development of the new mesalazine delivery systems would allow us to use higher dosages, which might provide additional therapeutic benefits to patients. However after more than 15 years of investigation of the newer mesalazine compounds involving thousands of patients, clear conclusions about the various dosages cannot be made.

For sulfasalazine there is a dose-response relationship for the treatment of quiescent ulcerative colitis. ${ }^{11}$ In a recent study the group that received a $3 \mathrm{~g}$ dose of Pentasa showed a clear trend towards prolonged remission in the intention to treat analysis, when compared with the $1.5 \mathrm{~g}$ group. ${ }^{8}$ No other data about ulcerative colitis in remission-maintaining studies and dose-response are available. In 1987 Schroeder et $a l .{ }^{14}$ studied the efficacy and safety of Asacol in the treatment of mildly to moderately active ulcerative colitis. With $1.6 \mathrm{~g}$ versus $4.8 \mathrm{~g}$ pH-dependent mesalazine tablet (Asacol) results showed 24\%complete and $50 \%$ partial responses in those patients receiving $4.8 \mathrm{~g}$ of mesalazine per day compared with $5 \%$ complete and $13 \%$ partial responses in those receiving placebo $(P<0.0001)$. At a dosage of $1.6 \mathrm{~g}$ per day, the response was twice as good as placebo, but the difference did not reach statistical significance. Recently these results have been confirmed with Pentasa. ${ }^{12}$ The $2 \mathrm{~g}$ and $4 \mathrm{~g}$ mesalazine doses produced significant endoscopic improvement compared with placebo $(P<0.004)$. Only the $4 \mathrm{~g}$ dose produced a significant histologic improvement compared with the placebo $(P<0.002)$.

Only one study found a statistically significant beneficial therapeutic effect of mesalazine in Crohn's disease at a dose of $4 \mathrm{~g} /$ day compared with $1-2 \mathrm{~g} /$ day and placebo. ${ }^{13}$ However no other data about doseresponse studies in Crohn's disease are available.

\section{Conclusion}

More and more investigators focus on therapeutic stratergies that target the recently characterized inflammatory mediators in IBD. Unfortunately the questions of the 1980s have not been answered. For instance, is one mesalazine preparation better than others? What is the appropriate dose for optimal treatment with oral preparations? Some investigators concentrate on meta-analysis studies in order to define the role and efficacy of mesalazine, however only prospective randomized controlled trials can answer all these questions. For many patients mesalazine makes a significant difference to their disease activity and quality of life. To our knowledge only one dose-response study will be presented within the next years about this issue, comparing 1.6 versus 3.2 Asacol and $3 \mathrm{~g}$ Claversal/Salofalk. Unfortunately these questions of the past will not be answered in the near future.

\section{References}

1. Svartz N. Salazyopyrin, a new sulfanilamide preparation. Acta Medica Scandinavia 1942; 110: 557-590.

2. Azad Khan AK, Piris J, Truelove SC. An experiment to determine the active therapeutic moiety of sulphasalazine. Lancet 1977; 2: 892-895.

3. Hanauer SB. Inflammatory bowel disease. New Engl J Med 1996; 334 : 841-848.

4. Sutherland LR, Shaffer EA. Sulfasalazine revisited: a meta-analysis of 5 -aminosalicylic acid in the treatment of ulcerative colitis. Ann Int Med 1993; 118: 540-549.

5. Wilding I. Scintigraphic evaluation of oral and rectal mesalazine products: pharmaceutical profiles experience. In: Pharmacokinetics and Safety Profile of Mesalazine. Proceedings from a Ferring symposium, Paris, 3 November 1996; 1-7.

6. Christensen LA. Release profiles and local/systemic availabilities of five oral 5-ASA -containing preparations. In: Rasmussen SN, ed. Pentasa in Ulcerative Colitis and Crohn's Disease. Symposium proceedings, Helsingor, Denmark, 1991. Chester: Adis International, 1992.

7. Jarnerot G. New salicylates as maintenance treatment in ulcerative colitis. Gut 1994; 35: 1155-1158.

8. Fockens P, Mulder CJJ, Tytgat GNJ, Blok P, Ferweda J, and the Dutch Pentasa Study Group. Comparison of the efficacy and safety of 1.5 compared with $3.0 \mathrm{~g}$ oral slow-release mesalazine (Pentasa) in the maintenance treatment of ulce rative colitis. Eur J Gastroenterol Hepa to 1995; 7: 1025-1030.

9. Runzi M, Layer P. Drug-associated pancreatitis: facts and fiction. Pancreas 1996; 13: 100-109.

10. Dent MT, Ganapathy S, Holdsworth CD, et al. Mesalazine induced lupuslike syndrome. Br Med J 1992; 305: 159.

11. Azad Khan AK, Howes DT, Piris J, Truelove SC. Optimum dose of sulphasalazine for maintenance treatment in ulcerative colitis. Gut 1980 ; 21: $232-240$.

12. Hanauer SB, Schwartz J, Robinson M, Roufail W, Arora S, Cello J, Safdi M Mesalazine capsules for the treatment of active ulcerative colitis: results of a controlled trial. Am J Gastroenterol 1993; 88: 1188-1197.

13. Singleton JW, Hanauer SB, Gitnick GL, Peppercorn MA, Robinson MG Wruble LD, Krawitt EL, and the Pentasa Crohn's Disease Study Group. Mesalamine capsules for the treatment of active Crohn's disease: results of a 16-week trial. Gastroenterology 1993; 104: 1293-1301.

14. Schroeder KW, Tremaine WJ, Ilstrup DN. Coated oral 5-aminosalicylic acid therapy for mildly to moderately active ulcerative colitis. A randomized study. NEngl J Med 1987; 317: 1625-1629.

\section{Received 11 March 1998;}

accepted 15 March 1998 


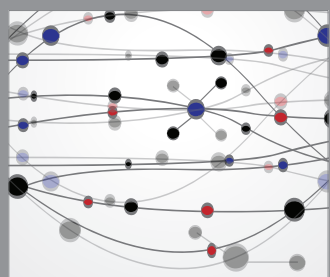

The Scientific World Journal
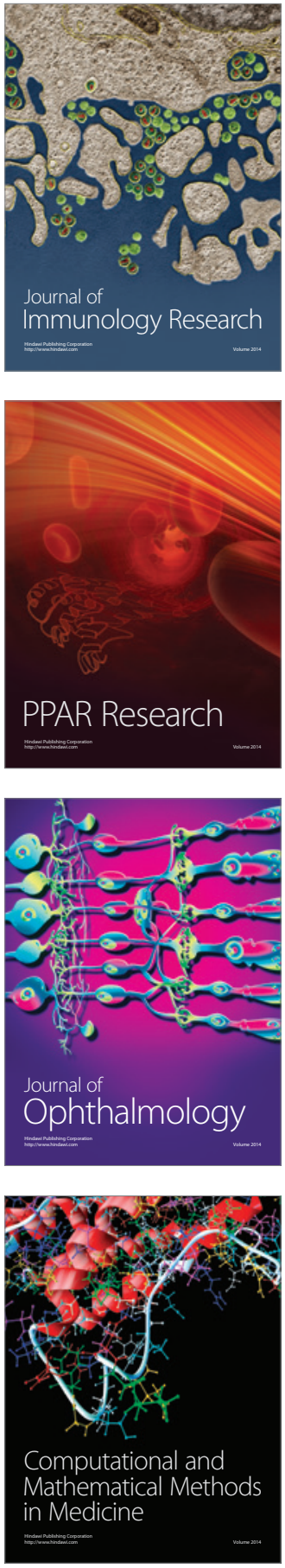

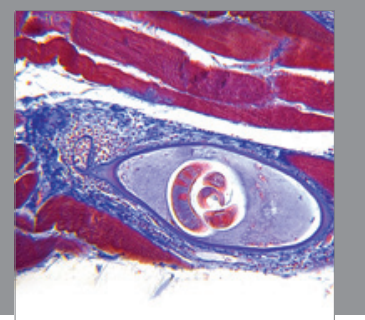

Gastroenterology

Research and Practice
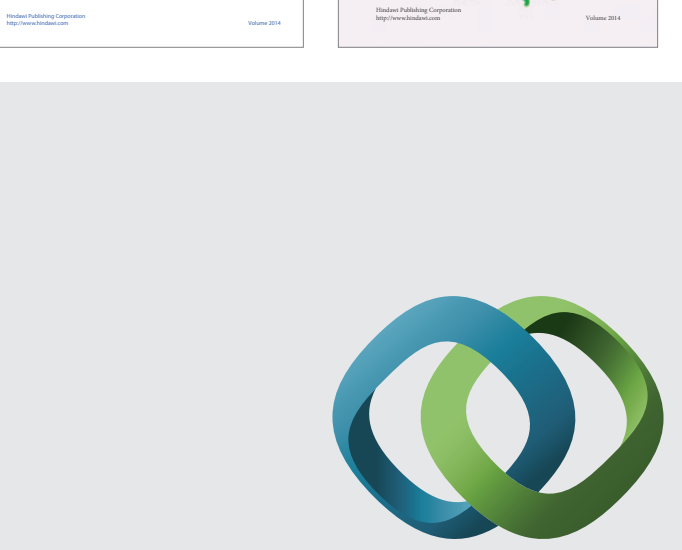

\section{Hindawi}

Submit your manuscripts at

http://www.hindawi.com
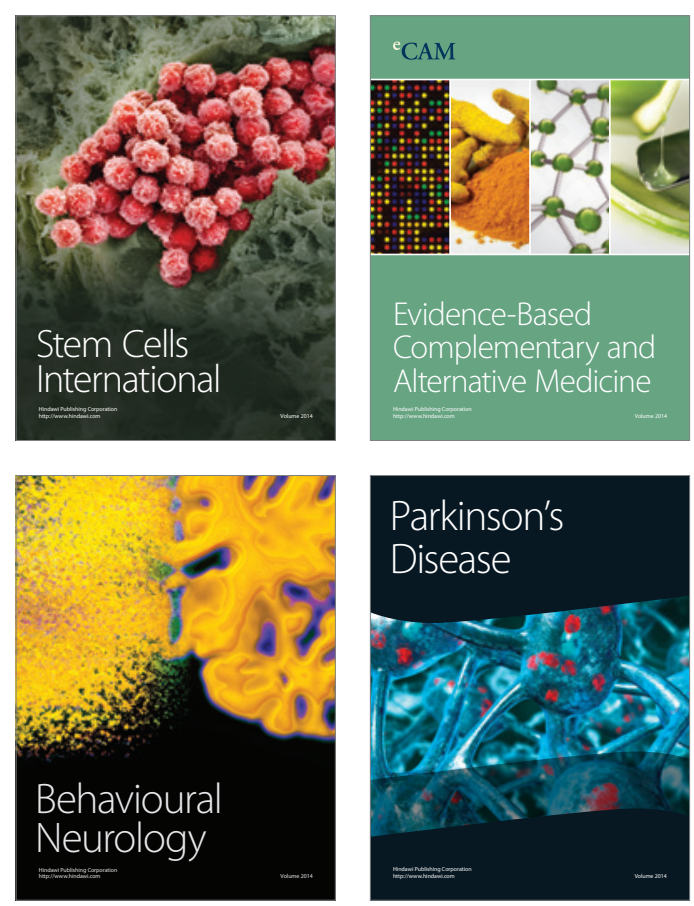

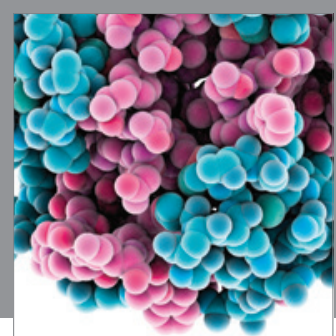

Journal of
Diabetes Research

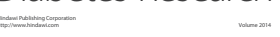

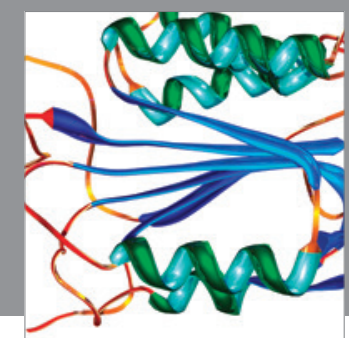

Disease Markers
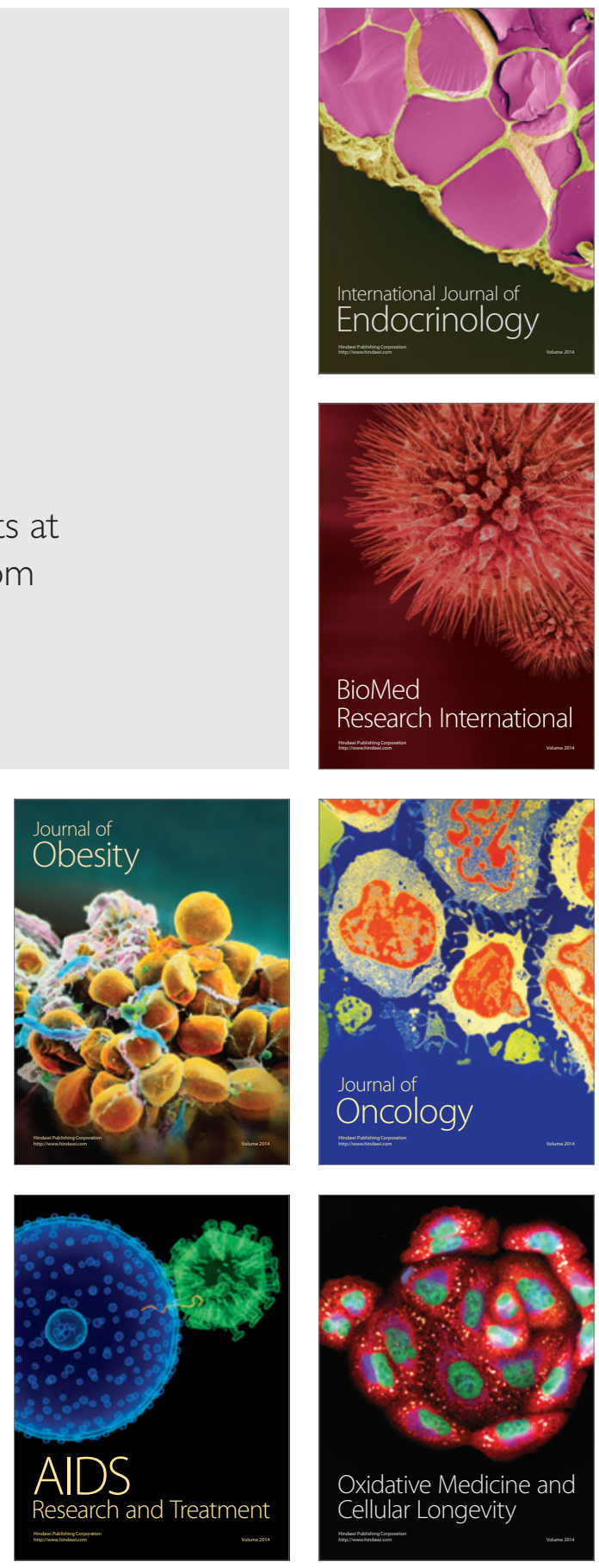